\title{
FINANCIAMENTO PÚBLICO E QUALIDADE DA EDUCAÇÃO: UMA ANÁLISE DO GASTO MUNICIPAL EM EDUCAÇÃO E DO ÍNDICE DE DESENVOLVIMENTO DA EDUCAÇÃO BÁSICA (IDEB)
}

\author{
Ana Beatriz Severo Xavier ${ }^{1}$ \\ Vitor de Moraes Peixoto ${ }^{2}$ \\ Maycon Rohen Linhares ${ }^{3}$
}

Resumo

A Constituição Federal de 1988 foi promulgada em um cenário onde a discussão acerca da descentralização e maior participação no regime democrático estava em pauta. Em um regime de colaboração e divisão dos custos operacionais do sistema de educação nacional, a constituição incentiva a descentralização dos recursos financeiros e das responsabilidades sobre a oferta do serviço educacional. Cabe aos municípios atuar prioritariamente na educação infantil e no ensino fundamental, destinando o mínimo de $25 \%$ de suas receitas na educação. O objetivo deste trabalho foi analisar a relação entre os gastos públicos municipais em educação e a qualidade da educação. A empreitada empregou uma metodologia quantitativa e utilizou indicadores político-eleitorais, de gasto por função e de qualidade da educação. Os principais achados deste trabalho foram os de que, em média, os gastos entre os partidos foram semelhantes, ou seja, partidos diferentes não imprimiram volumes diferentes de gasto na educação. E ao correlacionar o gasto municipal com educação e o desempenho destes mesmos municípios no IDEB, os resultados obtidos apontam para uma ausência de correlação linear entre as duas variáveis.

Palavras-chave: Financiamento Educacional; Municípios; Partidos Políticos; Democracia.

\section{Abstract}

The Federal Constitution of 1988 was promulgated in a scenario where the discussion about decentralization and greater participation in the democratic regime was on the agenda. The constitution encourages decentralization of financial resources and responsibilities on the provision of educational

\footnotetext{
${ }^{1}$ Estudante de Ciências Sociais na Universidade Estadual do Norte Fluminense Darcy Ribeiro (UENF) 2 Professor Associado na Universidade Estadual do Norte Fluminense Darcy Ribeiro (UENF)

${ }^{3}$ Mestrando de Sociologia Política na Universidade Estadual do Norte Fluminense Darcy Ribeiro (UENF)
} 
services, and brings a system of collaboration and division of operational costs of the national education system. The municipalities had to act primarily in early childhood education and primary education, earmarking a minimum of $25 \%$ of their income in education. The objective of this study was to analyze the relationship between municipal public spending on education and the quality of education. The project used a quantitative methodology and used politicalelectoral indicators, spending by function and quality of education. The main findings of this study were that, on average, expenditures between parties were similar, that is, different parties did not print different volumes of spending on education. And when correlating municipal spending with education and the performance of these same municipalities in the IDEB, the results obtained point to an absence of linear correlation between the two variables.

Keywords: Educational Financing; Municipalities; Political parties; Democracy.

\section{Introdução}

A partir dos anos 80 com as pressões populares em favor de um regime mais democrático, foi intensificado o debate sobre a delegação de poderes e responsabilidades aos governos locais. A excessiva centralização do poder e autoritarismo produzidos pelo período da ditadura, e as pressões populares em favor de um regime mais democrático e descentralizado, influenciaram em uma mudança no padrão das políticas sociais. Segundo Melo (2005) esta mudança ocorreu em vários âmbitos, desde a reorganização da estrutura das relações intergovernamentais até na ampliação e crescimento de despesas vinculadas as áreas sociais.

A descentralização do sistema de governo passou a ser interpretada como um processo que necessariamente levaria a uma maior democratização. Foi estabelecida uma ideia de causa e efeito entre o processo de descentralização e democratização, onde maior descentralização levaria necessariamente a maior democratização. De acordo com Arretche (1996), pareceu produzir-se acerca da descentralização um grande consenso, de que esta seria mais eficiente e elevaria o nível de bem-estar da população; fortalecendo e consolidando a jovem democracia brasileira neste processo.

A Constituição Federal publicada em 1988 incentiva a descentralização dos recursos financeiros e das responsabilidades sobre a oferta do serviço educacional. Para Rodrigues (2001) com a descentralização fiscal, resultado da nova distribuição de recursos entre os entes federados, os recursos nas instâncias 
dos estados e municípios crescem. Ao mesmo tempo em que a responsabilidade de atuação dos entes federados nos níveis de ensino também é redistribuída, a nova distribuição prioriza a atuação dos municípios na oferta do ensino infantil e ensino fundamental.

Segundo Vieira (2007), a carta magna de 1988 é a mais extensa de todas as constituições do Brasil em matéria de educação. Com um total de dez artigos sobre a temática, a carta trata da educação em diferentes níveis e aborda os mais diversos conteúdos; ao propor em seu artigo 206 à igualdade de acesso e permanência na escola a constituição oferece a participação de sujeitos antes excluídos do direito à educação.

Em 1996 é sancionada a Lei de Diretrizes e Bases da Educação Nacional, a LDB estrutura a organização do sistema educacional brasileiro em diferentes níveis: Educação Básica, composta pela educação infantil, ensino fundamental e ensino médio; e Educação Superior, composta pela graduação e pós-graduação. A LDB além de estruturar o sistema educacional brasileiro define em quais níveis da educação nacional os entes federados irão atuar prioritariamente. O esquema abaixo explicita isto:

Fluxograma 01: Financiamento da educação e Escopo de atuação e cada ente federado

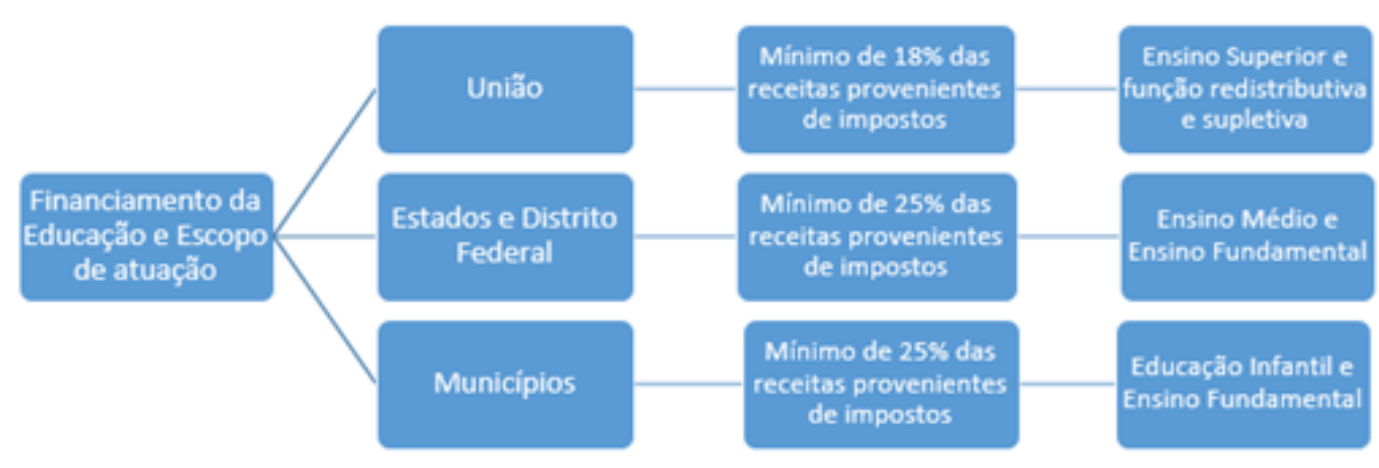

Fonte: Elaboração dos Autores

A União exerce papel redistributivo e suplementar. Além de definir parâmetros, competências e diretrizes para a educação nacional, a União deve atuar em caráter redistributivo e em regime de colaboração com os sistemas de ensino dos outros entes federativos, aplicando anualmente nunca menos de 18\% na manutenção e desenvolvimento do ensino. 
O papel dos Estados e do Distrito Federal é atuar em conjunto no Ensino Fundamental e Médio. Aos Estados e DF cabe a obrigação de atuar prioritariamente no Ensino Médio, e suprindo a carência de alguns municípios, no Ensino Fundamental; destinando também 25\% ou mais de sua receita, proveniente de impostos para o sistema educacional.

Os municípios devem obrigatoriamente oferecer educação infantil e o ensino fundamental. Os municípios devem atuar no ensino básico, especificamente, a educação infantil (creches e pré-escolas) e o ensino fundamental nos anos iniciais ( $1^{\circ}$ a $5^{\circ}$ ano) e anos finais ( $6^{\circ}$ a $9^{\circ}$ ano). Sendo permitida sua atuação em outros níveis de ensino apenas quando tiverem atendido plenamente as necessidades de sua competência. Com a delimitação de seu escopo de atuação e responsabilidades os municípios passam a ter um novo papel diante do cenário político nacional.

A descentralização contribuiu para a organização do sistema de política social com forte incentivo à atuação municipal. (Cavalcante 2014). O movimento de descentralização fez com os municípios adquirissem maior participação na formulação, implementação e avaliação das políticas públicas. Com a delegação de poderes aos governos locais o ensino básico, especialmente o ensino fundamental, passou por um processo de municipalização.

A efetivação do direito a educação se dá por meio da construção de políticas públicas. Para Souza (2006) a formulação de uma política pública constitui-se em um estágio onde os governos democráticos traduzem seus propósitos em programas e ações que visam produzir resultados no mundo real. A construção de uma política pública de educação busca a efetivação desse direito. Entretanto, isto levanta o questionamento se maior descentralização implicaria em maior eficiência das políticas públicas, especificamente, as políticas públicas de educação.

\section{Metodologia}

O artigo foi estruturado em dois momentos em que se utilizou de métodos quantitativos. No primeiro momento, foi feita a análise descritiva do IDEB e dos valores gastos pelas administrações municipais, em cada ano por meio da análise dos 5.570 municípios brasileiros, no período de 2009 a 2012. E no segundo momento, foi feita a análise da relação entre os valores do gasto com a função educação e do IDEB. 
Para a realização deste trabalho utilizou-se os seguintes indicadores: $O$ Índice de Desenvolvimento da Educação Básica (IDEB), para medir a qualidade da educação básica; e a média dos gastos municipais com educação, formado pelo volume de receitas que cada município destinou a função educação deflacionado com o auxílio do Índice Nacional de Preços ao Consumidor Amplo (IPC-A) do IBGE, tendo como base o ano de 2016.

Pararelacionar os resultados obtidos pelos municípios no indicador educacional utilizou-se o ciclo eleitoral de 2009 a 2012, relacionando-os com os resultados dos municípios no IDEB de 2009, 2011 e 2013. Partiu-se da premissa que o valor destinado por um governo à educação em um determinado ano, tem potencial para influenciar o resultado do indicador educacional calculado no ano seguinte. Para se observar o comportamento dos partidos no indicador de educação e gasto utilizou-se o método de comparação de médias.

Para medir a relação entre o financiamento da educação e o desempenho dos municípios nos anos iniciais e finais do ensino fundamental no indicador educacional, foi utilizado o coeficiente de correlação de Pearson. O coeficiente de correlação possui valor que varia de 0 a 1, onde 1 significa correlação perfeita e 0 nenhuma correlação, classificação utilizada também para valores negativos. Valores de 0 a 0,100 apresentam correlação nula, valores de 0,100 a 0,300 correlação fraca, valores de 0,300 a 0,600 correlação moderada, valores de 0,600 a 1 correlação forte.

\section{Resultados}

Entre os anos de 2007 e 2015 foram executadas cinco avaliações do Índice de Desenvolvimento da Educação Básica (IDEB), e mais uma realização pregressa, para o ano de 2005. Ao longo desta seção estão as principais constatações obtidas na análise introdutória destas realizações do IDEB para os municípios brasileiros, a análise do gasto municipal com a função educação e a análise da relação entre essas duas variáveis. A média dos resultados obtidos pelos municípios nas avaliações para os anos iniciais e finais do ensino fundamental aumentou. Ao mesmo turno em que ocorreu um aumento da variação das pontuações obtidas entre os municípios em cada ano e um aumento nas pontuações obtidas pelos conjuntos de municípios como um todo ao longo dos anos.

No que se refere aos gastos, os municípios têm destinado a cada ano maiores valores per capita para financiar a educação, esses valores, entretanto, não se 
diferenciam quando observado os gastos por partidos. Na análise da relação entre o desempenho dos municípios no IDEB e o valor destinados por esses a educação, o coeficiente de correlação indicou uma ausência de relação entre as variáveis.

Gráfico 01: IDEB das Escolas Municipais nos Anos Iniciais e Anos Finais do Ensino Fundamental (2005-2015).

ANOSINICIAIS

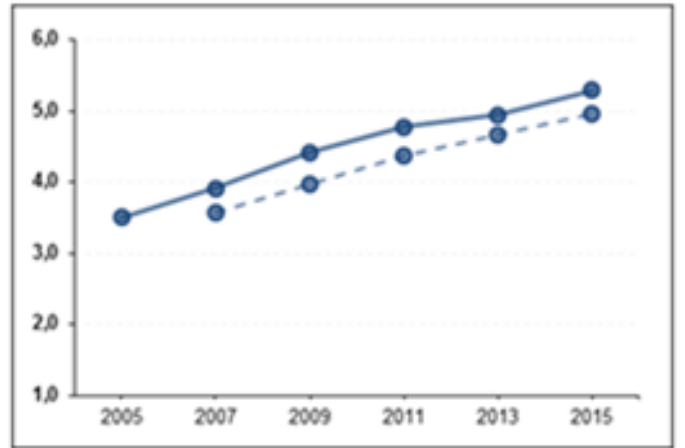

ANOS FINAIS

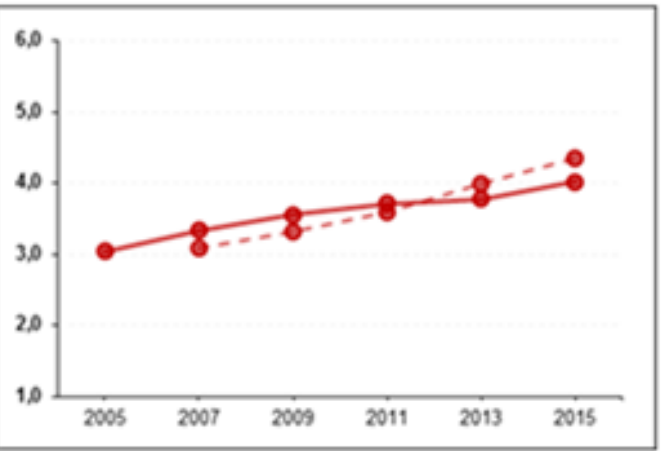

PROVEÇ̋ES

Fonte: Elaboração dos autores com base nos dados divulgados pelo Instituto Nacional de Estudos e Pesquisas Educacionais Anísio Teixeira (INEP).

No período analisado houve um aumento na média dos resultados obtidos no IDEB pelos municípios brasileiros no ensino fundamental como um todo. A análise do resultado dos municípios no indicador demonstrou um aumento na média do desempenho municipal nos anos iniciais do ensino fundamental ( $1^{\circ}$ ao $5^{\circ}$ ano) no IDEB na primeira avaliação, no ano de 2005, foi de 3,5. Já na última avaliação, no ano de 2015, foi de 5,3, um aumento de 1,8. A média de desempenho dos municípios brasileiros no IDEB para os anos finais do ensino fundamental ( $6^{\mathrm{a}}$ ao $9^{\mathrm{a}}$ ano) também sofreu um aumento. A medida de tendência central no ano de 2005 era de 3,0, valor que em 2015 passa para 4,0. Demonstrando um crescimento de 1,0 nos 10 anos de avaliação do indicador educacional. 
Financiamento público e qualidade da educação, pp. 75 - 86

Gráfico 02: IDEB das Escolas Municipais nos Anos Iniciais e Anos Finais do Ensino Fundamental por Partido do Prefeito (2009, 2011 e 2013). ${ }^{4}$

ANOSINICIAIS

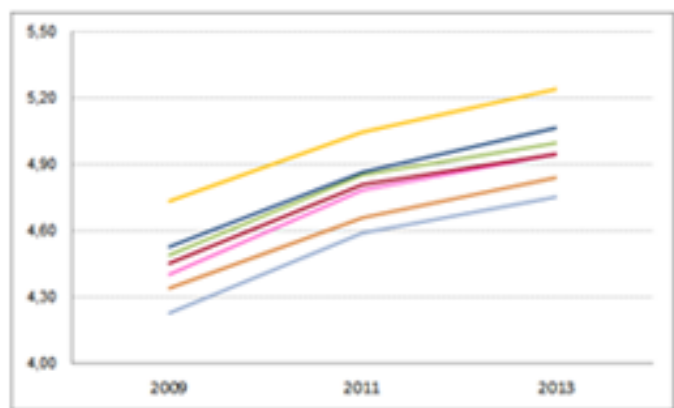

2000

2011

2023

ANOS FINAIS

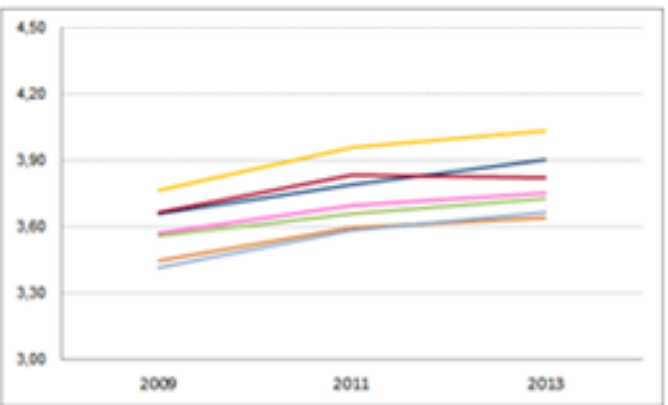

$-\mathrm{PMDB}-\mathrm{PSDB}-\mathrm{PT}-\mathrm{PP}-\mathrm{DEM}-\mathrm{PTB}-\mathrm{OUTROS}$

Fonte: Elaboração dos autores com base nos dados divulgados pelo Instituto Nacional de Estudos e Pesquisas Educacionais Anísio Teixeira (INEP) e Tribunal Superior Eleitoral (TSE).

No que diz respeito ao comportamento dos partidos no indicador educacional observou-se um aumento contínuo na média de desempenho, tanto para os anos iniciais quanto finais do ensino fundamental. Nos anos iniciais destaca-se o PDSB que apresentou o melhor desempenho no indicador nos anos analisados, com uma média de 5,24 no ano de 2013; seguido do PP, com o segundo melhor desempenho com média de 5,07 no IDEB em 2013; o DEM, em terceiro com 5,00; o PT em quarto com 4,95; PMDB, em quinto com 4,95; o PTB, em sexto com média de 4,94; e por último os partidos de menor expressão no cenário eleitoral nacional agregados na categoria OUTROS com 4,75 no ano de 2013. Já nos anos finais do ensino fundamental, o PSDB vem em primeiro lugar com média de desempenho de 4,04 no indicador no ano de 2013; seguido do PT com 3,83; em terceiro o PP, que no ano de 2013 tem um desempenho melhor que o PT com 3,90; em quarto o PMDB com 3,76; em quinto o DEM com 3,73; em sexto o PTB com 3,74; e por último a categoria OUTROS com uma média de 3,66.

\footnotetext{
${ }^{4}$ Para construção deste resultado e dos gastos municipais por partido foram utilizados os 6 partidos que possuíam a maior quantidade de prefeituras sob sua gestão, no período de 2009-2012, os partidos restante foram agregados na classificação "OUTROS".
} 
Financiamento público e qualidade da educação, pp. 75 - 86

Gráfico 03: Média de Gastos com Educação Per Capita dos Municípios Brasileiros (2008-2012).

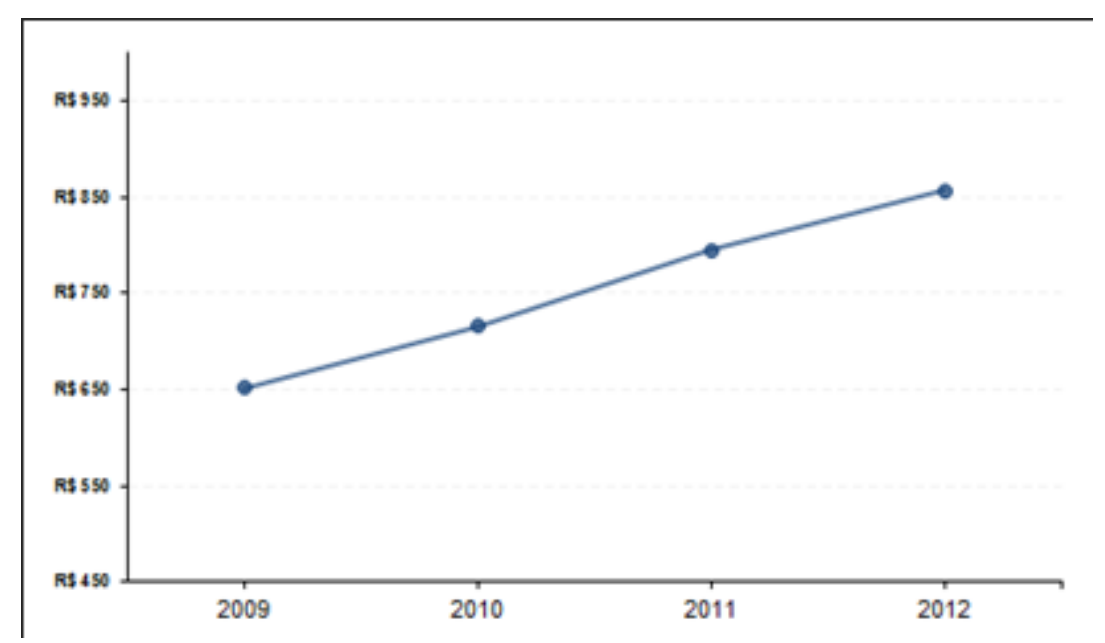

Fonte: Elaboração dos autores com base nos dados divulgados pela Secretaria do Tesouro Nacional (STN).

A média de gastos que os municípios brasileiros destinaram por habitante a função educação aumentou nos anos analisados. No ano de 2009 a média de gastos foi R \$651,99; valor que no ano de 2010 passou para $\mathrm{R} \$ 715,71$; no ano de 2011 o gasto médio foi para R\$794,84; e em 2012, último ano de análise, atingiu o valor de $\mathrm{R} \$ 857,28$ per capita. Uma diferença de $\mathrm{R} \$ 205,29$ no valor despendido pelos municípios por habitante para a educação em um período de 4 anos.

Gráfico 04: Média de Gastos com Educação Per Capita dos Municípios Brasileiros por Partido do Prefeito (2008-2012) ${ }^{5}$.

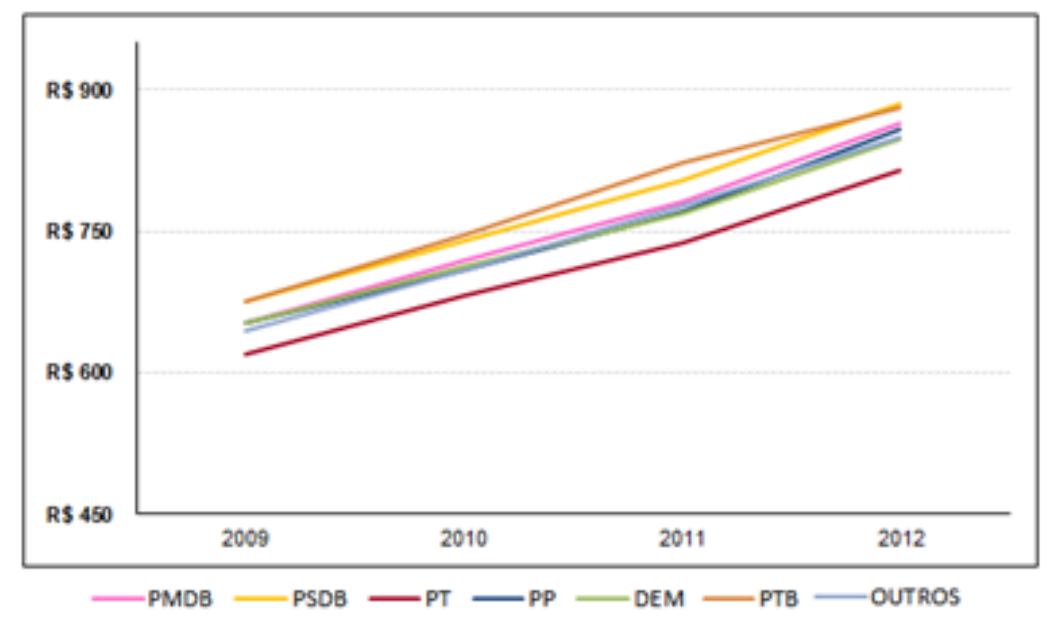


Fonte: Elaboração dos autores com base nos dados divulgados pela Secretaria do Tesouro Nacional (STN) e Tribunal Superior Eleitoral (TSE).

No que diz respeito aos gastos municipais por partido, foi possível observar que os gastos foram semelhantes, não havendo grande diferenciação da média de gastos por habitante entre os partidos. Os maiores valores per capita despendidos a educação vieram do PTB e do PSDB, seguidos de outros partidos com menor expressão no cenário nacional e pelo PMDB, com gastos semelhantes, logo após o PP e DEM, e por último o PT.

Durante o período analisado, o PTB possui a maior média de gasto per capita com educação, destinando no ano de 2009 cerca de R \$ 676,37 e no ano de 2012 $\mathrm{R}$ \$ 880,24 de sua arrecadação à educação. Em seguida o PSDB, com o segundo maior gasto, que apesar de ter despendido no ano de 2009 a média de R \$ 675,13 para a educação, no último ano de análise, ano de 2012, destinou valor superior ao PTB, em média R \$884,98 por habitante. Em seguida está PMDB que gastou em média por habitante o valor de $\mathrm{R} \$ 653,03$, no ano de 2009, valor que passa para $\mathrm{R} \$ 860,00$ no ano de 2012.

Em quarto lugar está a categoria OUTROS, formada pelos partidos de menor expressão no cenário eleitoral nacional, que gastaram em média no ano de 2009 R\$ 643,80, e no ano de 2012 R\$ 840,00. Logo após vem o PP, que no ano de 2009 gastou em média R\$ 652,98 por habitante, já no ano de 2012 passou para $\mathrm{R} \$ 850,00$, ultrapassando o valor dispendido pela categoria OUTROS. Em penúltimo lugar vem o DEM, que ano de 2009 destinou R \$653,31 por habitante para a educação, já no ano de 2012 gastou em média R $\$ 840,00$. Em último local, com o menor gasto per capita está o PT, que no ano de 2009 obteve uma média de gastos de R \$ 619,00 por habitante, e no ano de 2012 destinou em média cerca de $\mathrm{R} \$ 814,00$.

O desempenho dos municípios no indicador educacional foi correlacionado com os valores destinados por estes a educação. Após observar um aumento, tanto na média de resultado obtido pelos governos locais no IDEB, quanto na média de gastos destinados por esses a manutenção do sistema de ensino, estes dois indicadores foram correlacionados por meio da correlação de Pearson.

\footnotetext{
${ }^{5}$ Para construção desta análise foi retirado o município Manoel Urbano do Acre sob a gestão do PP, que no ano de 2011 gastou $\$ 80.000$ por habitante, elevando desta maneira a média de gastos do partido no referido ano. Por entender que este valor pode ter sido causado por um erro técnico, e para que este não influencie na análise do partido, este município foi descartado.
} 
Financiamento público e qualidade da educação, pp. 75 - 86

Matriz 01: Correlação do Gasto Municipal com Educação e o IDEB Municipal dos Anos Iniciais e Finais do Ensino Fundamental.

\begin{tabular}{|c|c|c|c|c|c|}
\hline \multirow{2}{*}{\multicolumn{2}{|c|}{$\begin{array}{l}\text { Gasto com Educação } \\
\text { Per Capita }\end{array}$}} & \multicolumn{2}{|c|}{ IDEB Anos Iniciais } & \multicolumn{2}{|c|}{ IDEB Anos Finais } \\
\hline & & 2011 & 2013 & 2011 & 2013 \\
\hline \multicolumn{2}{|c|}{$\rho$} & $-0,038$ & $-0,042$ & 0,029 & 0,032 \\
\hline \multirow[t]{3}{*}{2010} & Sig. (2) & 0,006 & 0,003 & 0,117 & 0,081 \\
\hline & N & 5.070 & 4.902 & 3.024 & 3.060 \\
\hline & $\rho$ & $-0,067$ & $-0,070$ & 0,021 & 0,026 \\
\hline \multirow[t]{2}{*}{2012} & Sig. (2) & 0,000 & 0,000 & 0,266 & 0,169 \\
\hline & N & 4.766 & 4.606 & 2.812 & 2.848 \\
\hline
\end{tabular}

Fonte: Elaboração dos autores como base nos dados divulgados pelo Instituto Nacional de Estudos Educacionais Anísio Teixeira (INEP) e Secretaria do Tesouro Nacional (STN).

A correlação do IDEB dos anos iniciais do ensino fundamental com o financiamento municipal para a educação apresentou classificação nula. Ao correlacionar o dinheiro gasto para financiar a educação no ano de 2010 ao IDEB obtido no ano seguinte, 2011, p apresentou o valor de -0,038; ao correlacionar o montante utilizado para financiar a educação no ano de 2012 com o IDEB de 2013, p apresentou o valor de -0,070. Com base no resultado do coeficiente de correlação, não há relação entre o financiamento municipal da educação e o IDEB.

Assim como nos anos iniciais, o indicador educacional dos anos finais do ensino fundamental correlacionado com os gastos em educação apresentou classificação nula e em alguns casos classificação fraca. Ao correlacionar os gastos em educação dos municípios no ano de 2010 ao desempenho posterior no indicador no ano de 2011, p obteve valor de 0,029. A última correlação apresentada, foi a do gasto dos municípios no ano de 2012 com o desempenho no IDEB de 2013, p apresentou o valor de 0,026. Assim como no caso dos anos iniciais do ensino fundamental, os valores obtidos no coeficiente correlação são baixos e indicam a ausência de relação entre o indicador educacional e os valores destinados a educação pelos municípios. 


\section{Discussão}

Os resultados encontrados por este estudo indicam que a qualidade do ensino fundamental tem melhorado como um todo. A melhora do desempenho da rede municipal de ensino no IDEB indica a presença de um avanço da qualidade do ensino ofertado pelos municípios. Os resultados apontam ainda uma ênfase nos anos iniciais do ensino fundamental, onde as escolas municipais obtiveram médias maiores do que as dos anos finais do ensino fundamental.

Estes resultados corroboram com os estudos de outros pesquisadores, como o feito por CROZATTI et al. (2014) que também encontraram um aumento do valor gasto pelos municípios na educação. Observou-se um aumento homogêneo na média dos valores per capita despendidos pelos municípios para a educação desde o ano de 2008. Apesar do claro crescimento do gasto, tanto absoluto, quanto per capita, este não possui qualquer relação ou poder de explicação do desempenho dos municípios no IDEB.

Ao correlacionar o gasto municipal com educação e o desempenho destes mesmos municípios no IDEB, os resultados obtidos apontam para uma ausência de correlação entre as duas variáveis. Ao utilizar o coeficiente de correlação de Pearson para medir a relação entre o gasto e o indicador educacional, observouse a presença de uma correlação nula, indicando uma ausência de correlação linear entre as variáveis.

\section{Conclusões}

As análises longitudinais permitem afirmar que os melhores desempenhos dos municípios no IDEB apontam na direção do aumento da qualidade da educação ofertada. Como mecanismo de avaliação de políticas públicas educacionais o IDEB tem permitido verificar um impacto positivo, além de demonstrar que com o passar das edições mais municípios tem aderido ao indicador, e aqueles já avaliados tem obtido, em média, resultados cada vez melhores.

Juntamente com o IDEB, o gasto dos municípios em educação com o passar dos anos tem crescido. Este trabalho constatou um aumento no valor gasto 
pelos municípios brasileiros por habitante para financiar a educação pública. Foi possível observar que os gastos são muito próximos não diferindo muito entre os partidos. Os maiores valores per capita despendidos a educação vieram do PTB e do PSDB, seguidos de outros partidos com menor expressão no cenário nacional e pelo PMDB, com gastos semelhantes, logo após o PP e DEM, e por último o PT.

Retomando a pergunta feita inicialmente no trabalho, os dados apresentados apontam para a ausência de relação entre maiores valores destinados a educação pelos municípios brasileiros e a melhora destes no indicador educacional. Os valores obtidos no coeficiente correlação de Pearson não foram significativos, permitindo a conclusão de que o aumento nos gastos municipais com educação não explica a melhora no desempenho dos municípios no IDEB. O resultado que aponta que outros fatores, que não os gastos municipais, estariam interferindo na melhora do indicador.

\section{Referências Bibliográficas}

Arretche, M., 1996. Mitos da descentralização: mais democracia e eficiência nas políticas públicas. Revista brasileira de ciências sociais, 11(31), p.127-152.

Cavalcante, P., 2014. A Implementação Municipal das Políticas Sociais: Uma Análise Espacial. Planejamento e Políticas Públicas, (42).

Crozatti, J. et al., 2014. Evolução do Gasto e do Financiamento da Educação nos Municípios Brasileiros de 2003 a 2012. Cadernos de Finanças Públicas, (14), p.201-220.

Melo, M.A., 2005. O sucesso inesperado das reformas de segunda geração: federalismo, reformas constitucionais e política social. Dados, 48(4), p.845-889.

Rodriguez, V., 2001. Financiamento da educação e políticas públicas: o Fundef e a política de descentralização. Cadernos Cedes, 21(55), p.42-57.

Souza, C., 2006. Políticas Públicas: Uma Revisão da Literatura. Sociologias, 8(16), p.20-45.

Vieira, S.L., 2007. A educação nas constituições brasileiras: texto e contexto. Revista brasileira de Estudos pedagógicos, 88(219), p.291-309. 